\title{
Are Feeding Modes Concealing Morphofunctional Diversity? The Case of the New World Parrotfishes
}

\author{
Lucía Pombo-Ayora ${ }^{\star t}$ and Jose Tavera \\ Laboratorio de Ictiología, Grupo de Investigación SEyBA, Departamento de Biología, Universidad del Valle, Cali, Colombia
}

\section{OPEN ACCESS}

Edited by:

Christian Marcelo Ibáñez, Andrés Bello University, Chile

Reviewed by:

Peter Wainwright,

University of California, Davis,

United States

Bruno Frédérich,

University of Liège, Belgium

*Correspondence:

Lucía Pombo-Ayora

lucia.pombo@correounivalle.edu.co

${ }^{\dagger}$ Present address:

Lucía Pombo-Ayora,

Red Sea Research Center, Division of Biological and Environmental

Science and Engineering, King

Abdullah University of Science

and Technology, Thuwal, Saudi Arabia

Specialty section:

This article was submitted to

Marine Evolutionary Biology,

Biogeography and Species Diversity,

a section of the journal

Frontiers in Marine Science

Received: 26 November 2020

Accepted: 22 March 2021

Published: 14 April 2021

Citation:

Pombo-Ayora L and Tavera $J$

(2021) Are Feeding Modes

Concealing Morphofunctional

Diversity? The Case of the New World

Parrotfishes.

Front. Mar. Sci. 8:634046.

doi: 10.3389/fmars.2021.634046
In functional ecology, morphology is expected to reflect function; however, occasional decoupling of these two can be found. In the case of feeding ecology, the diversity of the diet or diversity of the feeding modes within a clade is expected to be positively related to the diversity of the morphological traits involved in the feeding performance. Parrotfishes are separated into two main groups, the "reef" clade and the "seagrass" clade. Both groups have important differences in their evolutionary history. Still, more interestingly, they have important morphological and ecological differences. The genera Scarus and Sparisoma are the most specious genera of parrotfishes. They belong to each of those main groups, respectively. All Scarus species have the same feeding mode, while in Sparisoma, there are three different feeding modes. We want to test if the morphological jaw diversity of these genera corresponds with the diversity in their feeding modes. Using a disparity analysis of feeding traits within a phylogenetical framework, we did not find a relationship between functional feeding morphology and feeding modes of the American parrotfishes of the genera Scarus and Sparisoma. Interestingly we found that some muscular traits are the source of the high disparity in the genus Scarus. We explore some possible morpho-functional reasons for this phenomenon and reappraise the parrotfishes' scraper feeding mode's functional diversity. We also consider that there could be more ecological differentiation between Scarus species that we are aware of. Using an ancestral reconstruction of feeding modes of 52 species of parrotfishes, we found that the scraping feeding mode exhibited by all Scarus species is an evolutionary convergence with the scraping feeding modes performed by some Sparisoma species. Different selective pressures or ecological conditions may have shaped the differences in the feeding ecology and the feeding morphology of these two genera. Probably, key novel structures and muscular properties found in the Scarus species' jaw played an essential role in this genus's morpho-functional diversification. Finally, we propose that feeding modes may not fully capture the complexity of feeding ecology in parrotfishes.

Keywords: feeding ecology, morphological trait, phylogeny, Scarinae (Labridae), feeding modes

\section{INTRODUCTION}

Parrotfishes (Scarinae, Labridae) are vital members of the herbivorous fish community within coral reef ecosystems (Russ, 1984; Lewis, 1986). The subfamily Scarinae includes ten genera and around 100 species that inhabit tropical and subtropical reefs (Bellwood, 1994; Helfman et al., 2009; Parenti and Randall, 2011; Eschmeyer, 2019). They feed on algae during daylight; some species feed directly 
on epilithic algae, which grows on hard substrata like dead coral or rock, other species feed on seagrass and macroalgae (Bonaldo et al., 2014). The species of this family have a fundamental role in the resilience, maintenance, and recovery of coral reef ecosystems (Bonaldo et al., 2014; Clements et al., 2017). These fishes control algae proliferation and contribute to the balance between coral growth and coral erosion (Streelman et al., 2002; Helfman et al., 2009; Bonaldo et al., 2014). Although considered herbivores, parrotfishes have been classified into three different feeding modes. These are determined by their impact on the reef benthic substratum, the way they eat, and their oral and pharyngeal jaw morphology (Bellwood and Choat, 1990). Species can be classified as (1) Browsers, which feed on macroalgae or seagrass without having direct contact with hard substratum, (2) Scrapers, which feed by scraping epilithic algae that grow on dead coral or rock, and (3) Excavators, which feed by breaking pieces of coral to obtain epilithic and endolithic algae (Bellwood and Choat, 1990; Bellwood, 1994; Green and Bellwood, 2009; Helfman et al., 2009; Bonaldo et al., 2014).

The evolutionary history of parrotfishes has been previously studied using molecular (Bernardi et al., 2000; Streelman et al., 2002; Smith et al., 2008; Cowman et al., 2009; Price et al., 2010; Choat et al., 2012; Siqueira et al., 2019a) and morphological information (Bellwood, 1994). These studies have identified a clear break between two monophyletic groups within the subfamily, the "reef" clade scarinine (Scarus, Chlorurus, Bolbometopon, Hipposcarus, and Cetoscarus), and the "seagrass" clade sparisomatine (Sparisoma, Nicholsina, Leptoscarus, Calotomus, and Cryptotomus) (Streelman et al., 2002; Westneat and Alfaro, 2005; Smith et al., 2008; Choat et al., 2012; Aiello et al., 2017; Siqueira et al., 2019a). The "reef" clade (scarinine) is more taxonomically diverse ( $\sim 75$ species) with two main genera accounting for the majority of species (Scarus 52 and Chlorurus 18); species of this group feed either by scraping or excavating and are distributed in all tropical oceans. The "seagrass" clade (sparisomatine) has far fewer species ( $\sim 25$ species) with one genus accounting for the majority of species (Sparisoma 15; Froese and Pauly, 2017); in sparisomatine, species are performing each of the three feeding modes, occurring in all tropical oceans with most of the species distributed in the western Atlantic (Bernardi et al., 2000; Taylor et al., 2018).

Parrotfishes are commonly recognized by their beak-like teeth, which come from the fusion of individual teeth and results in a hard "beak" highly adapted to scrape or excavate hard substrata. The majority of parrotfishes species have this unique characteristic; however, a handful of species have different levels of teeth fusion or no fusion at all (Bellwood, 1994). Species without the beak or lower teeth fusion levels feed on macroalgae and belong to the "seagrass" clade (Bellwood and Choat, 1990). The mechanics and morphological traits involved in the feeding performance of parrotfishes has been previously studied and provided insight into the high degree of specialization of these fishes to inhabit reef environments (Bellwood and Choat, 1990; Streelman et al., 2002), the evolutionary rates of their feeding traits (Kazancioglu et al., 2009; Price et al., 2010), the unique mechanics involved in the movement of their jaws (Wainwright et al., 2004; Nanami, 2016; Wainwright and Price, 2018) and further modifications of the intramandibular joint found in Scarus, Hipposcarus, and Chlorurus species (Bellwood, 1994; Wainwright et al., 2004). However, further steps aiming to understand the relationships between functional morphology and the fishes' ecological roles in a phylogenetical framework are still missing.

This study is focused on two genera of American parrotfishes included in each of the major clades, scarinine and sparisomatine, which have previously been ecologically differentiated by their feeding behavior. We included nine scraping species of the genus Scarus and six species of the genus Sparisoma, which display all identified feeding modes (scrapers, browsers, and excavators) (Bellwood, 1994; Bruggemann et al., 1996; Streelman et al., 2002; Cardoso et al., 2009; Bonaldo et al., 2014). We characterized the morpho-functional diversity of the feeding apparatus by measuring muscular and skeletal features of the oral jaws. We measured the adductor mandibulae muscle's length and weight and modeled its work potential and physiological crosssectional area. We also included measurements of the mechanical advantage of the opening and closing of the jaw, the horizontal mouth gape, and the premaxilla's ascending process length. All traits together were used to calculate the morpho-functional disparity (Foote, 1993, 1997) among species within each genus and evaluate it within an evolutionary context to answer the following questions: (1) Is the feeding mode diversity reflected in the morphological diversity of each genus? We hypothesize that the genus Sparisoma would have higher morphological diversity of the feeding mechanics than the genus Scarus, given that more feeding modes have been described for this group. (2) Which traits are varying the most within each genus and therefore contribute more to the disparity? (3) Do the transitions between feeding modes across the parrotfish evolutionary history influence the ecological disparity between Scarus and Sparisoma? We seek to explore if the morphology of each feeding modes is influenced by evolutionary convergence or by biogeography?

\section{MATERIALS AND METHODS}

\section{Species Included and Morpho-Functional Measurements}

Our morphological analyses include specimens of nine species of the genus Scarus and six from the genus Sparisoma. They were all coming from the Colombian Caribbean and Pacific Waters. We only used adult specimens, and we refer to their feeding modes at this stage. Species, sampling location, number of individuals, and feeding modes are summarized in Table $\mathbf{1}$.

Feeding modes were obtained from the literature. The software MandibLever (Westneat, 2003) was used to model four traits of the adductor mandibulae muscle subdivisions A2 and A3: muscular work (muscles A2 and A3) and physiological crosssectional area (muscles A2 and A3). We obtained the planar morphological measurements from digital photographs taken with a metric scale. We recorded the weight of the muscles A2 and A3 from freshly dissected individuals (Figure 1).

We analyzed each photo with the software Image 1.5 .0 (Abramoff et al., 2004). We recorded the weight of the adductor 
TABLE 1 | Species examined, including feeding modes, number of individuals examined, and sampling location.

\begin{tabular}{llll}
\hline Species & $\begin{array}{l}\text { Feeding } \\
\text { mode }\end{array}$ & N & Sampling location \\
\hline Scarus ghobban & Scraper & 11 & Gorgona Island, Pacific \\
Scarus guacamaia & Scraper & 1 & Santa Marta, Caribbean \\
Scarus rubroviolaceus & Scraper & 2 & Gorgona island, Pacific \\
Scarus perrico & Scraper & 1 & Gorgona island, Pacific \\
Scarus coeruleus & Scraper & 1 & Serrana Cay, Caribbean \\
Scarus coelestinus & Scraper & 1 & Serrana Cay, Caribbean \\
Scarus vetula & Scraper & 2 & Serrana Cay, Caribbean \\
Scarus iseri & Scraper & 2 & Santa Marta, Caribbean \\
Scarus taeniopterus & Scraper & 3 & Santa Marta, Caribbean \\
Sparisoma viride & Excavator & 2 & Santa Marta, Caribbean \\
Sparisoma aurofrenatum & Scraper & 4 & Santa Marta, Caribbean \\
Sparisoma rubripinne & Browser & 2 & Santa Marta, Caribbean \\
Sparisoma chrysopterum & Browser & 2 & Santa Marta, Caribbean \\
Sparisoma atomarium & Browser & 1 & Serrana Cay, Caribbean \\
Sparisoma radians & Browser & 1 & Albuquerque Cay, Caribbean \\
\hline
\end{tabular}

mandibulae muscles A2 and A3 to the nearest $0.0001 \mathrm{~g}$. Additionally, the length of the premaxilla ascending process, the horizontal mouth gape, and the head length were measured to the nearest $0.05 \mathrm{~mm}$ with a digital caliper. We calculated the opening and closing lever mechanisms of the lower jaw by computing the mechanical advantage as in levers divided by out levers (Figure 1; Wainwright and Richard, 1995). For details in the jaw landmarks to make the measurements refer to Wainwright et al. (2004).

We chose the weight of adductor mandibulae muscles as it can be used as a rough indicator of their force-producing capacity (Wainwright et al., 2004). Therefore, it can be an indicator of which substratum parrotfishes can potentially feed on (Bellwood and Choat, 1990). The physiological crosssectional area of those adductor mandibulae subdivisions are complementary measurements to the weight of the muscles and are also indicators of force-producing capacity (Westneat, 2004). Mechanical advantage is a measure of the ability of the jaw lever system to transmit strength and velocity toward the jaw tip (Collar et al., 2005). Muscular work represents the strength the adductor mandibulae muscle exerts, times the distance of muscular contraction during the jaw closure (Westneat, 2003). The ascending process length of the premaxilla was used as a proxy for the capacity of the fish to protrude the jaw during feeding; higher values represent greater protrusion (Gosline, 1981; Hulsey et al., 2010; Bellwood et al., 2015). Finally, the mouth gape was examined because it relates to the size of the prey a fish can eat (Wainwright and Richard, 1995). In parrotfishes, it represents the area of the substratum that they could potentially cover while feeding.

\section{Phylogenetic Relationships and Temporal Calibration}

With the aim of placing our analysis in a phylogenetical framework, we used published sequences available in GenBank (Sayers et al., 2011) to build a phylogeny of 52 species which includes time-calibrated clades. Species were distributed as follows: 34 Scarus, 9 Sparisoma, 2 Chlorurus, 2 Hipposcarus, and 1 Nicholsina, Leptoscarus, Bolbometopom, Cryptotomus, and Calotomus (Supplementary Table 1). We used partial sequences of 12 genes: 12S, 16S, COI, CytB, D-loop, BMP4, DLX2, OTX1, RAG1, RAG2, S7, and TMO. The majority of sequences come from molecular phylogenetic analysis done by Streelman et al. (2002); Westneat and Alfaro (2005), Smith et al. (2008), and Aiello et al. (2017). The sequences were aligned with Clustalw (Thompson et al., 1994) and Muscle (Edgar, 2004) algorithms. To reduce the number of partitions and to identify the nucleotide substitution model of each gene, we used the software PartitionFinder (Lanfear et al., 2012). We used the nucleotide substitution model GTR for

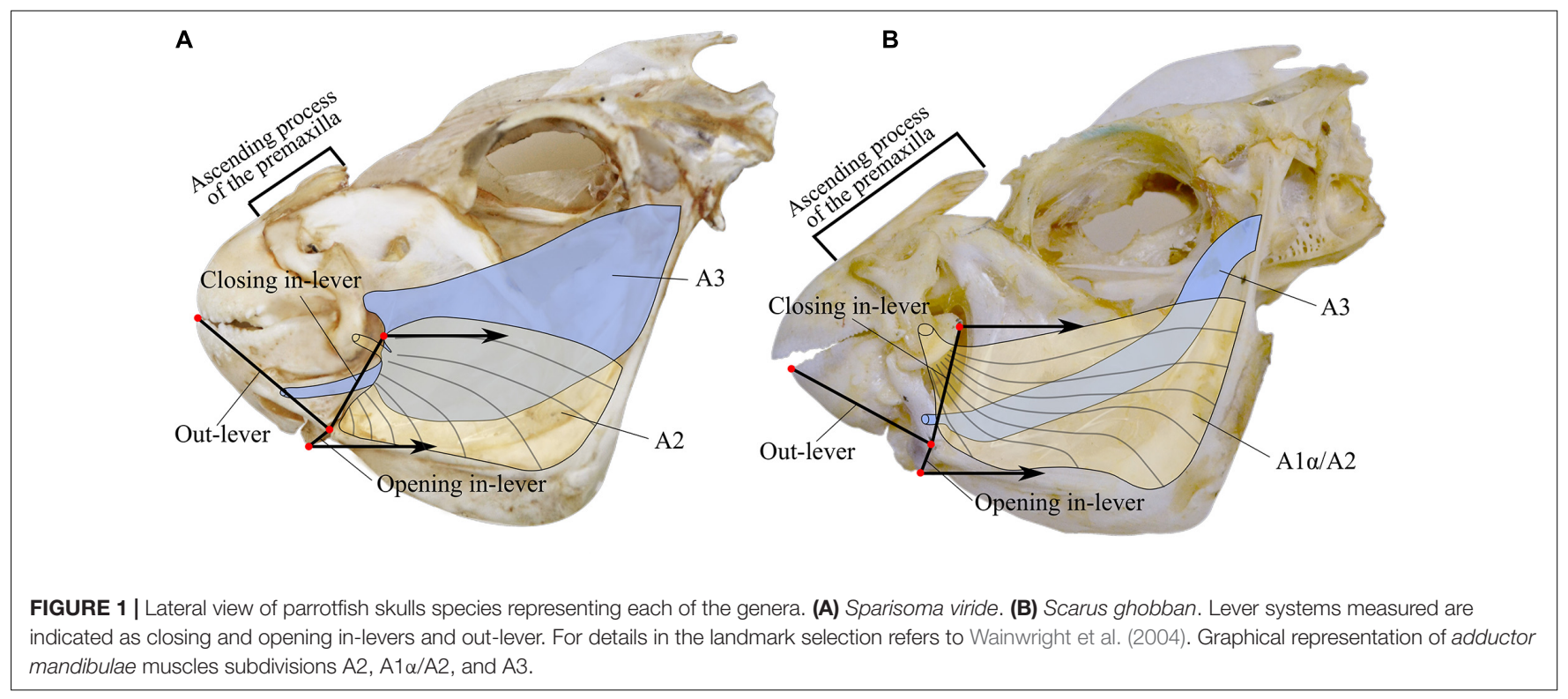


the following genes: 16S, 12S, COI, RAG2, TMO, OTX1, and S7. For CytB, D-loop, BMP4, and RAG1, we used the HKY model, and for DLX2, the TN93 model. The Bayesian phylogeny inference and estimation of divergence times were performed with BEAST 2.4.1 (Drummond and Rambaut, 2007) using the online platform CIPRES (Miller et al., 2015). Timecalibration was done using fossil-based legacy dates taken from the posterior distribution density of the estimated age for the Scarine clade as in Choat et al. (2012). Birth-Death was used as the speciation model. The analysis was run for $5,000,000,000$ generations, sampling trees, and parameters every 500,000 generations. To verify convergence and chain mixture, we used the software Tracer v1.6 (Rambaut et al., 2014), using an ESS value $>200$ as an indicator of adequate convergence and mixture. A maximum clade credibility tree was obtained from TreeAnnotator to summarize tree information. A set of trees sampled from the posterior distribution were used to perform all posterior analyses.

\section{Phylogenetic Principal Component Analysis and Morpho-Functional Disparity}

To answer our first research question: is the feeding mode diversity reflected in the morphological diversity of each genus? We calculated morphological diversity and explored it by conducting a phylogenetic principal component analysis (pPCA), in which we create convex hulls around each genus, indicating as well the feeding mode of each individual species. Since the species included in this study differ significantly in their body length, its effect was removed to focus only on trait differences. We used the size correction method proposed by Wroe et al. (2005) and Grubich et al. (2012), which calculates trait quotients based on the residuals of the phylogenetic linear regression of the traits against the head length (size). Phylogenetic regressions were done using the package phytools (Revell, 2012). We used the cube root of the muscle weights and the muscles' square root of the PCSA. Data were $\log 10$ transformed before the linear regressions. Closing and opening mechanical advantages were not transformed at all given that these traits are ratios and are not influenced by the size. Thus, the relationship between the head length and weight of the muscles, physiological muscular cross-sectional area, muscular work, mouth gape, and length of the premaxilla ascending process was used to estimate quotients: adductor mandibulae weight quotient (Weight(A2)Q and Weight(A3)Q), adductor mandibulae physiological cross-sectional area quotient [(PCSA(A2)Q) and (PCSA(A2)Q)], mouth gape quotient (MGQ), muscular Work quotient (WorkA2Q and WorkA3Q), and premaxilla ascending process length quotient (APLQ).

We used the average of the quotients and traits per species to run the pPCA (Blomberg and Garland, 2002; Revell, 2009) using the covariance matrix, with the phytools package in $\mathrm{R}$ (R Development Core Team, 2013). For this pPCA, we used the pruned tree that contains the 16 species for which we have morphological measurements. We used the Broken-Stick model (King and Jackson, 1999) to define how many components should be analyzed. Subsequently, we plotted the morphospace and calculated polygons and centroids for each genus.

We ran the disparity analysis with the scores of each species using the scores from all ten dimensions of the pPCA. All scores were re-sampled through a bootstrapping method to obtain confidence intervals. The disparity was calculated with two metrics in order to account for different aspects of morphological distribution along the morphospace (Guillerme et al., 2020): the sum of variance in every dimension and the sum of the distance of each species to the centroid of their group polygon (Guillerme, 2018). A $t$-student test was run to test for differences between Scarus and Sparisoma disparities. This test was conducted using the R library DispRity (Guillerme, 2018). To evaluate how the disparity has accumulated over evolutionary history, we performed a disparity through time (DTT) analysis, as implemented in Harmon et al. (2003). We evaluated the rate of jaw morphological evolution in relation to the diversification of Scarus and Sparisoma clades with the R library geiger (Harmon et al., 2008). We used the trait matrix and the pruned phylogenetic tree to simulate the average disparity under Brownian motion (BM) model (10000 simulations) and compared it with the observed disparity. The so-called morphological disparity index (MDI) for each clade was calculated. Positive MDI values indicate greater than expected subclade disparity (García-Navas et al., 2017), while negative values indicate lower than expected subclade disparity (Slater et al., 2010). Statistical differences between the BM simulated disparity and observed disparity were evaluated for each genus.

To answer our second question: Which traits are varying the most within each genus and therefore contribute more to the disparity? We examined all traits separately, comparing the coefficient of variation (calculated as the ratio between the standard deviation and the mean) of each trait quotient in both Scarus and Sparisoma. Additionally, different rates of continuous evolution were tested among clades for all independent traits, using likelihood assuming BM (O'Meara et al., 2006). This analysis was performed in the R library Phytools (Revell, 2012).

\section{Ancestral Feeding Modes Reconstruction}

To answer our third question: Does the transitions between feeding modes across the parrotfish evolutionary history influence the ecological disparity between Scarus and Sparisoma? We modeled the ancestral transitions of feeding modes within the parrotfish phylogeny, using an equal rates transition matrix and Bayesian stochastic character mapping (Huelsenbeck et al., 2003) over a sample of 1000 trees randomly sampled from the posterior distribution of the Bayesian phylogenetic reconstruction, using the library phytools (Revell, 2012) included the software R (R Development Core Team, 2013). As body size is an important trait related to ecological behavior, we map it on the phylogenetic tree as a bar representing the maximum size reported of each species. Maximum length information was obtained from the following sources: Robertson and Allen (2015); Robertson and Van Tassell (2015), and Froese and Pauly (2017). 


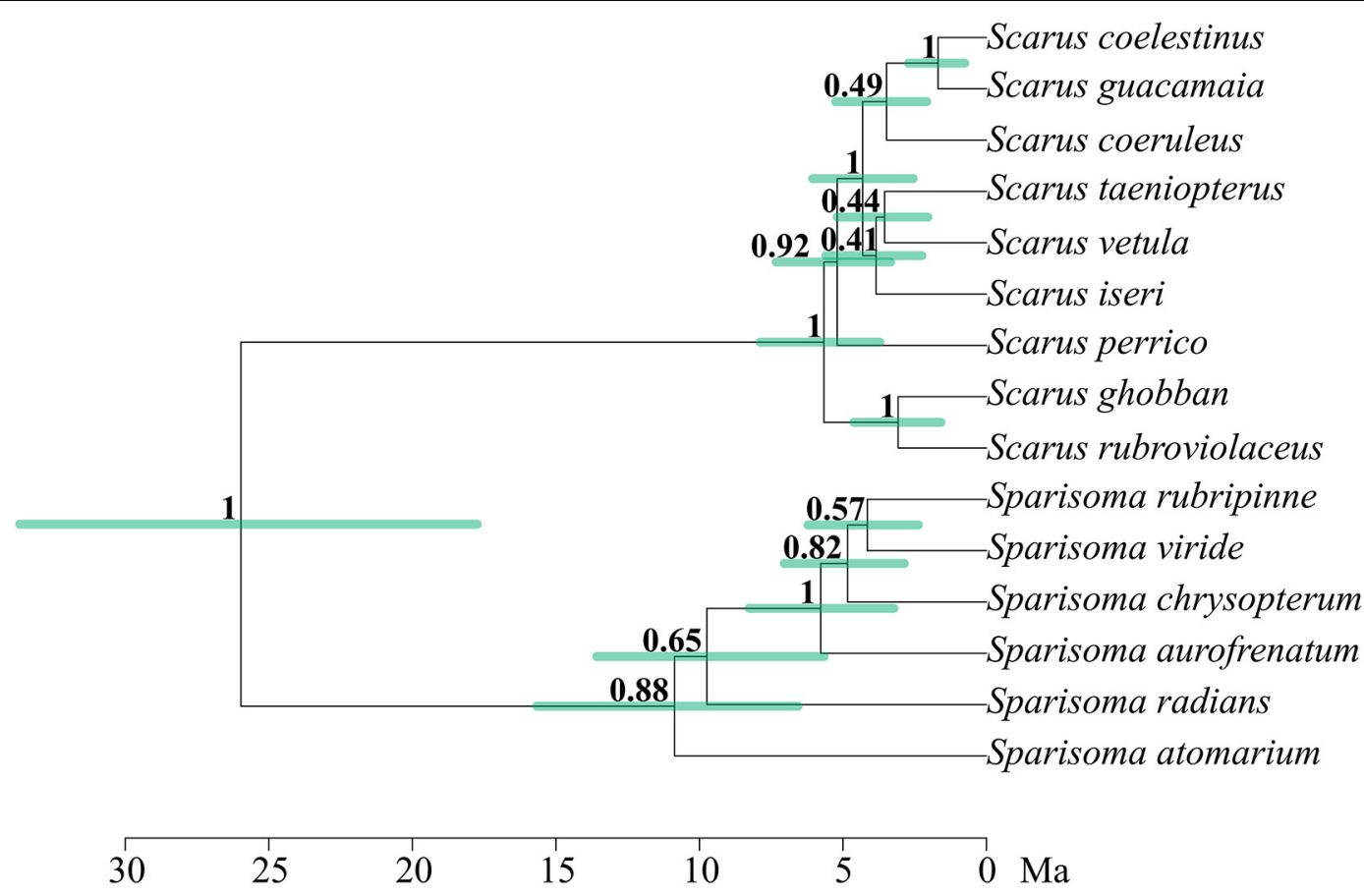

FIGURE 2 | Multilocus phylogeny of the parrotfishes species used in this study. The number in each node represents the support by Bayesian posterior probabilities. Green bars represent high-density probability with 95\% credibility for the node age. Branch lengths are in a million years.

\section{RESULTS}

\section{Parrotfish Phylogenetic Tree}

Figure 2 shows the phylogenetic relationships between the parrotfish species included in this study. The separation between Scarus and Sparisoma is strongly supported, with a posterior probability (PP) of 1 . Our phylogenetic reconstruction of the evolutionary relationships of 52 parrotfish species (Figure 3) concurs almost completely with the topology and divergence of previous works (Bellwood, 1994; Bernardi et al., 2000; Smith et al., 2008; Choat et al., 2012; Aiello et al., 2017; Siqueira et al., 2019a). The recovered estimated age for the genus Scarus was 8.02 mya ago (HPD: 5.01-10.9), and an estimated age for the genus Sparisoma 12.53 mya (HPD: 7.7-17.8) (see Supplementary Material for HDP bars and estimated age of all clades). Although, while all other phylogenies locate Leptoscarus in the "seagrass" clade along with Sparisoma, Cryptotomus, Nicholsina, and Calotomus genera, our reconstruction locates Leptoscarus in the "reef" clade with the remaining parrotfish genera. However, the node is not strongly supported $(\mathrm{PP}=0.69)$ (Supplementary Material).

\section{Phylogenetical Principal Component Analysis}

According to the broken-stick model, the first two axes of the pPCA analysis are enough to account for most of the variation and thus are the ones interpreted. Both summarized $80 \%$ of the total morpho-functional traits variance (66 and $14 \%$, respectively). On the first component, there was no unique trait accounting for the majority of the variance. Instead, most traits had similar loading values, except for both opening and closing mechanical advantages, which had substantially smaller loadings. In the second component, mouth opening mechanical advantage had the greatest load. See loadings of all traits in the first two dimensions in Table 2.

Figure 4 shows pPC1 and pPC2. The area occupied by the genus Scarus in these two dimensions is considerably larger than the area occupied by the genus Sparisoma. Scrapers, which include all Scarus species and Sparisoma aurofrenatum are broadly distributed across the morphospace. All four browser species Sparisoma atomarium, Sparisoma chrysopterum, Sparisoma radians, and Sparisoma rubripinne are separated in both axes. Sparisoma viride, the only excavator parrotfish included in this group, is not significantly separated from other Sparisoma in the morphospace, which means that this species does not have an extreme combination of traits despite its different feeding mode. This result clearly suggests that parrotfishes do not cluster according to feeding modes or that the selected traits are not capturing all of this ecological information.

\section{Feeding Traits Morpho-Functional Disparity}

Scarus species showed greater morpho-functional disparity than Sparisoma (Figures 5A,B). This result indicates the same as the pPCA (Figure 4), where Scarus is morpho-functionally more diverse than Sparisoma on the selected traits regardless of the feeding mode. 


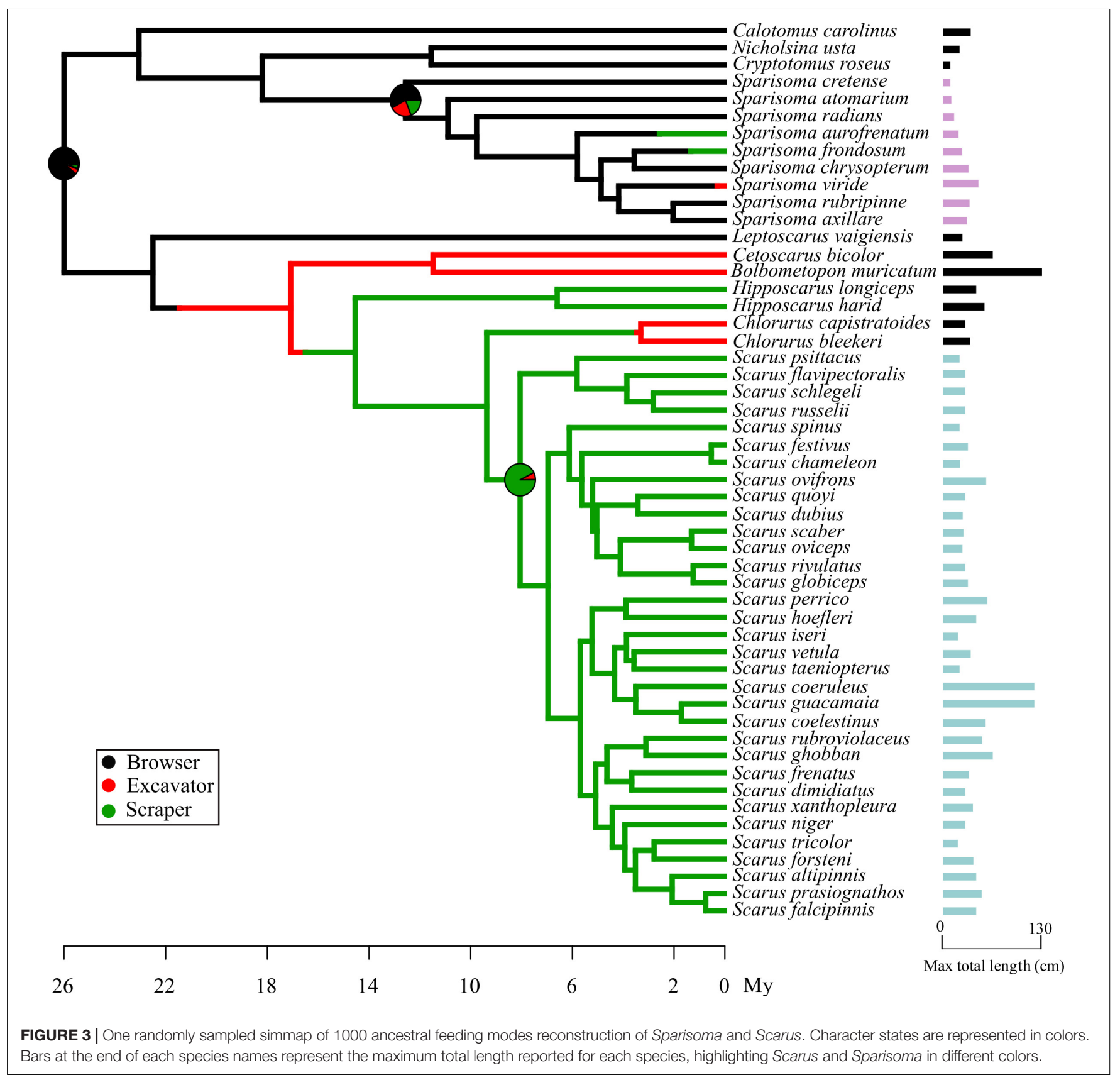

Figures 5A,B are the graphical representation of the disparity. The point in each disparity bar represents the median. The $t$-student test indicates that there are significant differences in disparity measured as the sum of variances (Figure 5A, $t=159.2481, \mathrm{df}=16621.12, p \leq 0.000)$, and as the sum of the distance to the centroid (Figure 5B, $t=309.9466$, $\mathrm{df}=14362.13, p \leq 0.000)$. Table 3 summarizes the observed and bootstraped disparity as well as the $2.5 \%, 25 \%, 75 \%$, and $97.5 \%$ disparity quantiles.

The DTT analysis indicated that Scarus (mean DTT $=1.34$ ) has higher average DTT than Sparisoma (mean DTT $=0.56$ ), results that supports our morphological disparity analysis.
Positive MDI for morphological variables were found on Scarus (0.79) while negative on Sparisoma (-0.18) (Figures 5C,D). However, the differences from BM expectation were not statistically significant in either case (Scarus, $p$-values $=0.994$; Sparisoma, $p=0.513)$. In Scarus, there is a pulse of high disparity rates at the end of the Pliocene ( $2.6 \mathrm{my}$ ) (Figure $5 \mathrm{C}$ ). This observed disparity pulse rises above the BM simulations and the $95 \%$ confidence interval, suggesting a rapid diversification of some Scarus species during this period of time. No pulse was identified in Sparisoma, where observed disparity decreases smoothly and follows the BM simulation tendency (Figure 5D). Figure 6 illustrates the ratio of evolutionary rates (Scarus 
TABLE 2 | Phylogenetic principal component analysis (pPCA) loadings for each trait in the first two principal components PC1 and PC2.

\begin{tabular}{lrr}
\hline Morpho-functional traits & PC1 & \multicolumn{1}{c}{ PC2 } \\
\hline Weight A2 muscle & -0.27965240 & -0.44911831 \\
Weight A3 muscle & -0.37127963 & 0.04345098 \\
PCSA A2 muscle & -0.36111745 & -0.12036620 \\
PCSA A3 muscle & -0.37968779 & 0.03439915 \\
Work A2 muscle & 0.28793758 & -0.33740479 \\
Work A3 muscle & -0.37015671 & 0.13645407 \\
Mouth gape & -0.37003044 & 0.09220504 \\
Ascending process length of the premaxilla & -0.37457107 & 0.07929554 \\
Mouth opening mechanical advantage & -0.06257599 & -0.74795747 \\
Mouth closing mechanical advantage & -0.09116760 & -0.27210623 \\
\hline
\end{tabular}

relative to Sparisoma), of each trait. The rates of morphological evolution were significantly different among clades in WorkA2 and PCSAA2 trait. In both cases higher rates were found on
Scarus, 12 times higher WorkA2 and 13 times higher PCSAA2 compared to those of Sparisoma (Table 4).

Species trait variation within each genus is illustrated in Figure 7. A more uniform pattern of variation between traits in all Sparisoma species can be observed, as opposed to fluctuating values found in Scarus. The difference in the coefficient of variation of each trait between genera indicates that PCSA(A2) (31.5), Work(A2) (31.2) are the traits that show less variation in Sparisoma compared to Scarus. The WorkA3 presented higher variation in Sparisoma than in Scarus. The remaining traits have smaller differences in the coefficient of variation between both genera.

\section{Ancestral Feeding Modes Reconstruction and Maximum Total Length Variation}

The main result of this analysis shows that parrotfishes feeding modes appeared at different time points of their evolutionary

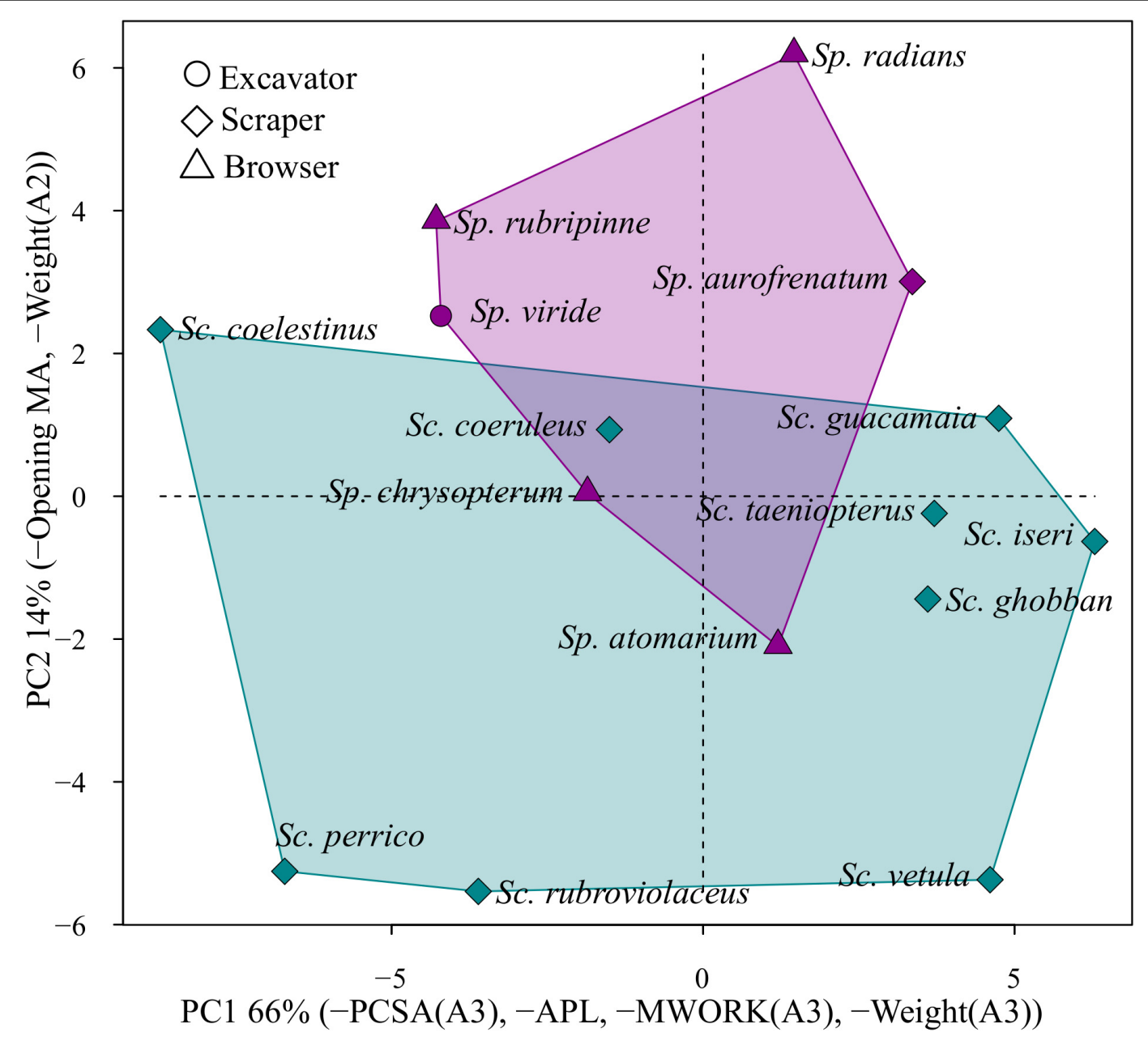

FIGURE 4 | Morphospace of parrotfishes functional feeding traits. The colors represent the genera, being blue Scarus and purple Sparisoma. The first two principal components describe $79 \%$ of the variation in the covariance matrix. The axis label indicates the morpho-functional characters with the greater loadings. Symbols represent different feeding modes. 

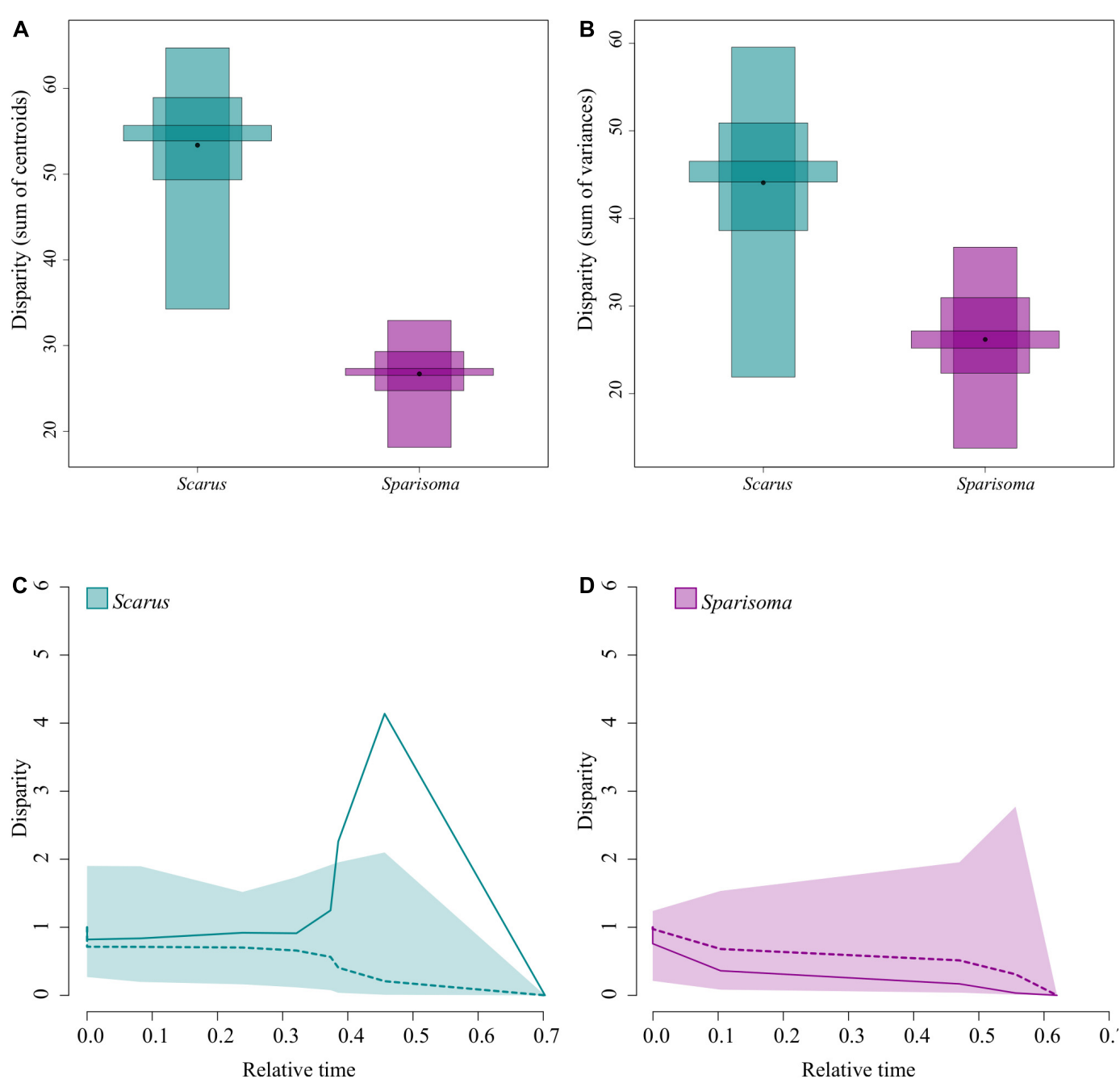

FIGURE 5 | The disparity between Scarus and Sparisoma species. The black point represents the mean disparity, and the inner partitions represent quantiles with 10, 50, and $95 \%$ confidence. (A) The disparity is measured as the sum of distances to the centroid. (B) The disparity is measured as the sum of variances in the morphospace. (C) Scarus jaw morphological disparity through time plot. (D) Sparisoma jaw morphological disparity through time plot. In the DTT plots, the solid line is the observed disparity, and the dashed line is the average disparity under the BM model. The shaded area represents the $95 \%$ confidence intervals from 10000 BM simulations.

TABLE 3 | Morpho-functional disparity of the American species in the genera Scarus and Sparisoma.

\begin{tabular}{|c|c|c|c|c|c|c|c|}
\hline Genus & $n$ & Obs. disparity & Mean (bootstrap) & $2.5 \%$ & $25 \%$ & $75 \%$ & $97.5 \%$ \\
\hline Scarus & 9 & 50.17 & 45.76 & 22.03 & 38.97 & 51.42 & 60.18 \\
\hline \multicolumn{8}{|c|}{ Sum of centroids } \\
\hline Scarus & 9 & 57.93 & 55.04 & 34.46 & 49.55 & 59.16 & 64.95 \\
\hline Sparisoma & 6 & 30.01 & 27.09 & 18.31 & 24.94 & 29.50 & 33.13 \\
\hline
\end{tabular}

history. In Figure 3, the pie on the crown node of all parrotfishes indicates that there is a high probability that their ancestor was a browser. According to our results, scrapers and excavators emerge later in the Sparisoma clade. The Scarus ancestor was most likely a scraper with a low probability of being an excavator. The maximum total length of each species is represented as the size of the bar at the end of the species name (Figure 3). While the maximum length of Sparisoma species used in the morphological comparison varies between $15 \mathrm{~cm}$ (S. atomarium) and $64 \mathrm{~cm}$ (S. viride) (SD $18.9 \mathrm{~cm})$, Scarus species exhibit higher lengths with values found between $27 \mathrm{~cm}$ (Scarus iseri) and $120 \mathrm{~cm}$ (Scarus coeruleus) (SD $31.3 \mathrm{~cm})$. 


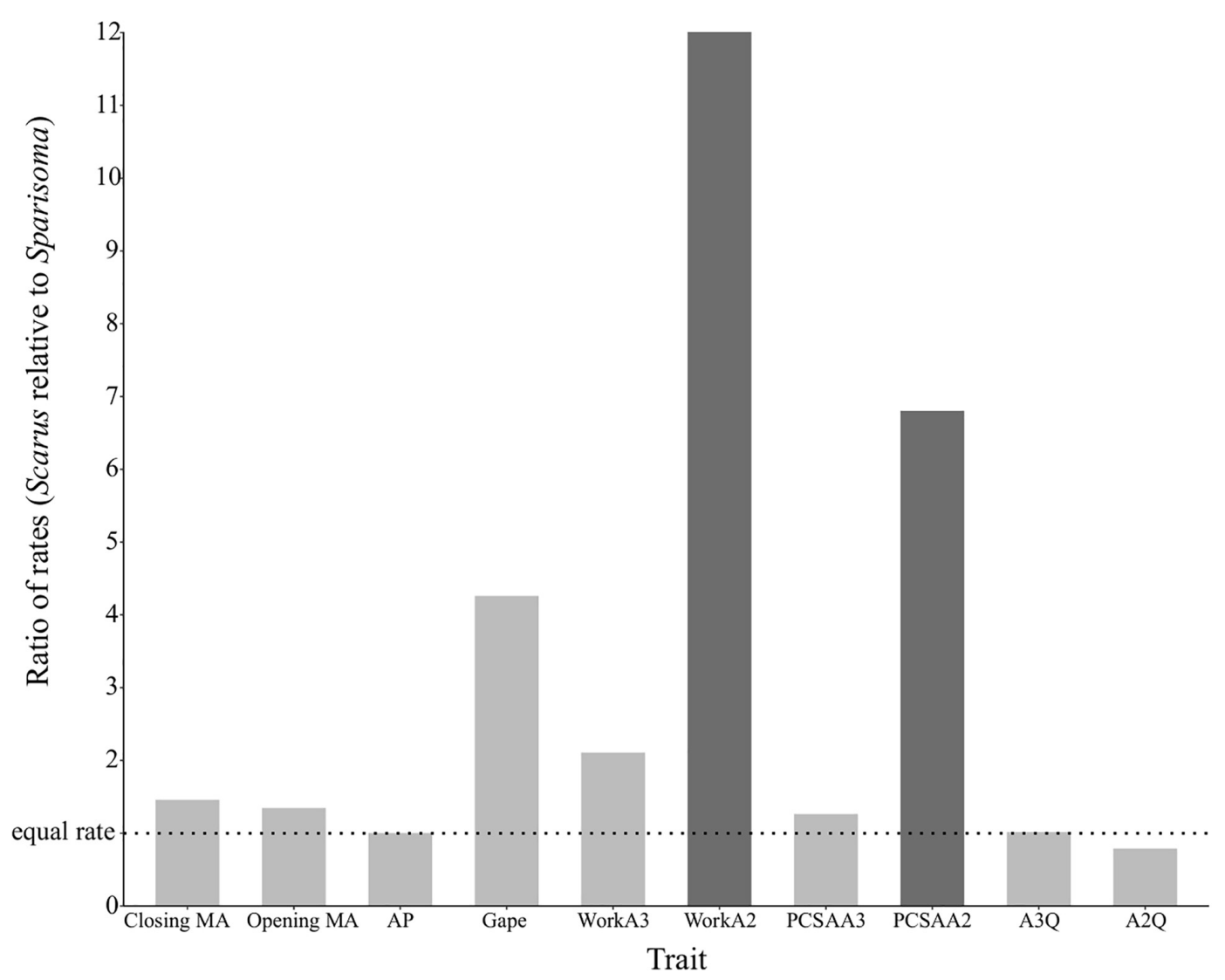

FIGURE 6 | Relative rates of jaw morphological evolution. The rates are depicted as Scarus relative to Sparisoma. Statistical differences in trait evolution ( $p$ $\left.\left(\chi^{2}\right)<0.05\right)$ are indicated as darker bars. Relative rates $>1$ indicate faster rates in Scarus, while $<1$ indicate slower rates in Scarus.

\section{DISCUSSION}

The high morphological disparity exhibited by Scarus species that feed only by scraping, compared to Sparisoma parrotfishes that include scrapers, browsers, and excavators (Bellwood, 1994; Bruggemann et al., 1996; Bernardi et al., 2000; Streelman et al., 2002; Smith et al., 2008; Cardoso et al., 2009), indicates that there may be no correspondence between feeding mode diversity and feeding trait variation. Scarus species use the same feeding mode while having a greater morpho-functional diversity compared to Sparisoma, which seems to be morpho-functionally constrained. A mismatch between morphological diversification and functional diversity has been already found in parrotfishes by Price et al. (2010), with the clade containing the genera Scarus, Chlorurus, and Hipposcarus, accumulating higher jaw morphological disparity than other genera of parrotfishes. Similar cases of decoupling between ecology and morphology have been found in damselfishes by Frédérich et al. (2014) and Olivier et al. (2017). However, there can be many different morphological ways to deliver the same function (Wainwright et al., 2005). Nevertheless, this is not the typical scenario, and it can be counter-intuitive given the expected match between ecology and morphology, as it has been found in other morpho-ecological studies, where high feeding morphological disparity is directly related to high diet diversity (Collar et al., 2005; Carlson and Wainwright, 2010; Price et al., 2010; Burress et al., 2020).

It is well known that the clade composed of Scarus, Chlorurus, and Hipposcarus possess a novel modification of the lower jaw (Bellwood, 1994). This modification is an intramandibular joint between the quadrate and the articular bones. Price et al. (2010) proposed that the presence of this modification could be providing this clade with a higher morphological diversity compare to the rest of the parrotfishes genera. The intramandibular joint is a relatively flexible structure that allows more parameters to vary and adds more degrees of freedom within the oral jaws leading to higher mechanical complexity, which can turn into additional morphological diversity (Vermeij, 1973; Konow et al., 2008; Ferry-Graham and Konow, 2010; Price et al., 2010; Konow and Bellwood, 2011). The traits we choose to compare Scarus and Sparisoma are not affected by the presence or absence of the intramandibular joint, except by the opening and closing mechanical advantage of the lower jaw, which are not likely to represent the whole mechanism of opening and closing the jaw in the genus Scarus (Wainwright et al., 2004). However, both of the mechanical advantages do not have high loadings in the pPCA or exhibit substantial differences in the coefficient of variation between both genera. Price et al. (2010) found a higher morphological disparity in 


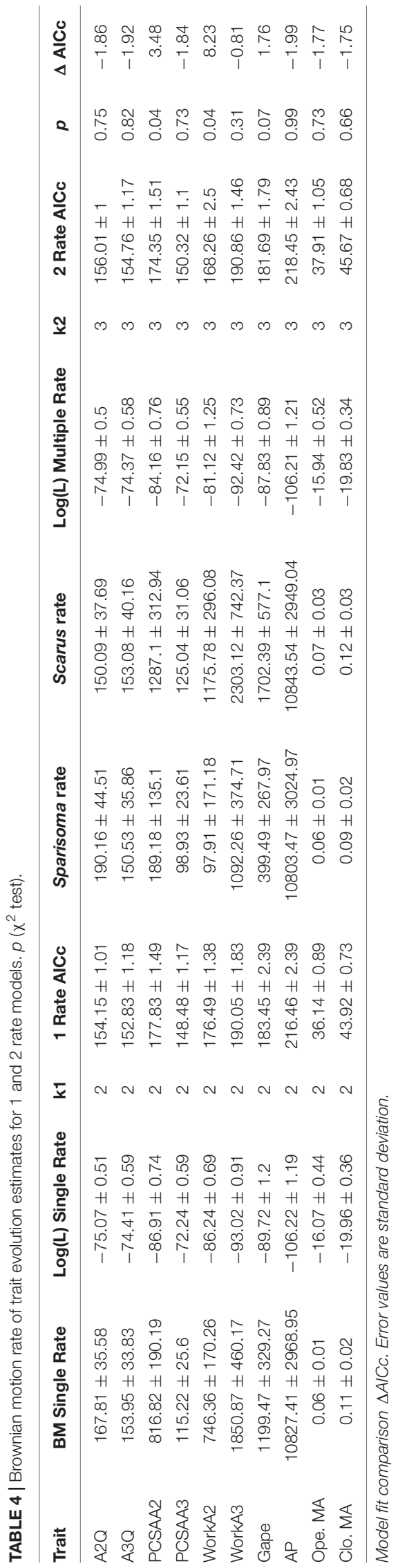

the clade Scarus-Chlorurus-Hipposcarus than the rest of the parrotfishes genera. They tested their hypothesis using rates of evolution of their morphological traits, focusing on the intramandibular joint's presence and absence. We found a greater morphological disparity in the genus Scarus than in the genus Sparisoma, but we did not test the influence of the intramandibular joint and instead used a multidimensional morphospace occupancy approach. Yet we found similar results as Price et al. (2010), from a different perspective and can attribute the morphological variability within Scarus to different traits (e.g., muscular traits). Both studies thus complement each other strengthen the evidence of a high morphological disparity in the genus Scarus.

It seems likely that the absence of detailed assessments of the feeding behavior or the microhabitat association of Scarus species could result in an underestimated level of ecological diversity within the genus. Only until recent studies (Nicholson and Clements, 2021) parrotfishes, especially those categorized as scrapers, were pooled together as a single feeding unit. Nicholson and Clements (2021) started to unravel the feeding microhabitat level of association using a finer description of the substrata these fishes feed on. As suggested by Clements et al. (2017) and supported by Nicholson and Clements (2021), it seems that parrotfishes microecological differentiations could be triggered by their feeding behavior as microphages that actually target a very diverse range of feeding substrate. Thus, it seems that Scarus feeding behavior is rather more diverse than it was thought before, but it was overlooked because this ecological differentiation is not obvious. To be able to confirm that microecological diversity is positively correlated with morphological diversity in these groups of parrotfishes, a deep and detailed assessment of the feeding microhabitat use by Sparisoma species needs to be done. Another under-explored possibility of ecological differentiation within the genus Scarus is the scale of space used inside the reef they inhabit. The size of the fish is related to the use of habitat, the distribution on the reef, and the home range size (Nash et al., 2013). As can be noted in Figure 3, there is a higher variation in the maximum standard length among species of the genus Scarus than among the species of the genus Sparisoma. The size differences are observed considering all the species used for the phylogenetic analysis and the species used only in the morphological analysis. We should not discard the possibility that ecological differentiation of the species of the genus Scarus could be mediated by their body size.

Beyond the lack of detail in microhabitat use and sizemediated morphological differentiation, it is possible that we do not understand or have underestimated the diversity of the scraping feeding mode in parrotfishes. For Scarus species, the mechanics of their scraping may be as diverse as their jaw morphology. As proposed by Bellwood and Choat (1990), the classification of feeding modes is related to the physical effect on the reef benthos by the feeding activities of these fishes. The scraping feeding mode has been defined as the feeding activity where there is little removal of calcareous material while grazing epilithic algae and is characterized by weak and brief bites (Bellwood and Choat, 1990). That definition is useful for ecological assessments of bioerosion impact on the reefs by 
parrotfishes; however, it excludes the mechanical complexity found in the jaws of Scarus species and ends up being simplistic to describe the mechanics behind the biting performance of these fishes. If we could measure the diversity of scraping by this genus of parrotfishes and compare that diversity with the morphological diversity of their jaws, we may find a concordance between jaw morphology, function, and ecology. Further research focusing on the ecological feeding differentiation of the genera Scarus will be a milestone in the understanding of parrotfish's functional roles in reef ecosystems.

We found that the major differences between genera are in traits related to muscular performance. The mechanical work quotient of the muscle A2 (WorkA2), the mechanical work quotient of the muscle A3 (WorkA3), and the physiological crosssectional area quotient of the muscle A2 (PCSAA2) showed the highest disparity in terms of the coefficient of variation. These three traits are directly related to muscle performance during lower jaw-closing (Westneat, 2003). Interestingly, the results of the trait evolutionary rates comparison showed that only WorkA2 and PCSAA2 were statistically higher in Scarus compared to Sparisoma. Unlike the results from Price et al. (2010), that compared parrotfishes from the genera Scarus, Chlorurus, and Hipposcarus (species that possess an intramandibular joint), with the rest of parrotfishes genera (species with no intramandibular joint), our comparison Scarus (parrotfishes with an intramandibular joint) with Sparisoma (parrotfishes with no intramandibular joint) did not show statistical differences in the rates of evolution of the mechanical advantages (closing and opening). We then observed higher evolutionary rates and high trait variation of traits directly related to muscle performance. The adductor mandibulae muscle in parrotfishes is divided into three sections, A1, A2, and A3, the last two are directly involved in the closing of the jaw, while the A1 is attached to the upper jaw and is involved in jaw protrusion (Bellwood, 1994; Wainwright and Richard, 1995; Westneat, 2003). The shape, the relative size, and the insertion points of the A2 and A3 substantially differ from Scarus to Sparisoma (See Figure 1; Bellwood and Choat, 1990). In Scarus $\mathrm{A} 3$, it is thin and narrow, while in Sparisoma, it is larger and wider. Muscle A2 also presents structural differences between the genera. In Scarus, it is fused with a portion of the A1 muscle forming a singular muscular complex $\mathrm{A} 1 \alpha / \mathrm{A} 2$, while in Sparisoma, it is described as a large superficial muscle (Bellwood and Choat, 1990). Our results suggest that some of those features of the adductor mandibulae muscle in the genus Scarus might confer more freedom to vary the lower jaw-closing performance at an intraspecific level compared to Sparisoma. It seems that the observed disparity is driven by the muscular properties of the adductor mandibulae.

Our results of the DTT support the morphological disparity analysis results based on the morphospace, where Scarus has higher disparity than Sparisoma. Also, MDI values found on trophic traits on Scarus (0.79) and Sparisoma $(-0.18)$ (Figures 5C,D) may suggest contrasting patterns. Negative MDI values indicates that most disparity occurs among subclades, thus occupying smaller, isolated areas of the morphospace (García-Navas et al., 2017). On the other hand, a positive MDI value is indicative that disparity is distributed primarily within subclades and thus a stronger overlap in the morphospace will be expected (Reaney et al., 2018). Despite these tendencies, there are no statistical differences between the observed and the simulated disparity under BM in any genera, thus we cannot conclude that within clade disparity is higher or lower than the among clade disparity. However, we can still state that Scarus DTT is higher than Sparisoma. The high pulse in Scarus disparity around the end of the Pliocene $(\sim 2.6 \mathrm{my})$ is in agreement with several contemporary events in parrotfishes biogeographical history and changes in coral communities assemblages. For instance, the highest species diversification within the Scarus clade occurred in the Pliocene (Smith et al., 2008; Choat et al., 2012; Siqueira et al., 2019b) as well as the arrival of Scarus rubroviolaceus and Scarus ghobban to the eastern Pacific (Choat et al., 2012). Big changes in coral reef community dynamics (Renema et al., 2016; Mao et al., 2018) triggered by fluctuations in the sea level (de Boer et al., 2012) might have pushed morphological adaptations in American Scarus to face the rapid coral community changes. This result reinforces the idea that both biogeographical events like the colonization of the eastern Pacific and the Caribbean of the Scarus species and the rapid adaptation to changing environments may have triggered jaw morphological diversification in this genus.

We found high morpho-functional diversity with low ecological diversification in the genus Scarus, while the opposite tendency was observed in the genus Sparisoma. The functional redundancy of morphological structures can enable ecological convergence, and such modifications of existing morphologies in response to similar ecological requirements can lead to the evolution of morphological diversity (Young et al., 2010). In some animal clades, the morphological disparity is the results of single or repeated ecological convergence, that is, the case of birds in which ecological convergence could potentially be a cause of greater morphological diversity where the position of species within morphological space comes together with major niche axes, highlighting an important role of evolutionary adaptation (Pigot et al., 2020). On the other hand, Moen et al. (2013), using frogs, found that both evolutionary convergence and biogeography are important in explaining similarity in species traits over large spatial and temporal scales. Our SIMMAP results indicate that the scrapping feeding mode in Scarus appeared only once during its evolution, ruling out the possibility of ecological convergence, which could potentially be a cause of greater morphological diversity. This may suggest that biogeography more than ecological convergence may be paired with feeding mode evolution. This hypothesis concurs with previous works (Bernardi et al., 2000; Streelman et al., 2002; Choat et al., 2012). Initial exposure to seagrass meadows and later to reefs environments by Sparisoma species corresponds to the late appearance of scraping ( $\sim 3$ mya) and excavating ( $<1$ mya) feeding modes in the genus. On the other side, scarinine species occupied reef environments since their early diversification times (Streelman et al., 2002), which is paired with the early appearance of the scraping feeding mode ( $\sim 16.5$ mya). We cannot certainly demonstrate with our data if the transitions of feeding modes influenced their habitat selection or it was the other way around. Our results, supported by other time-calibrated phylogenies (Cowman et al., 2009; Kazancioglu et al., 2009; Choat et al., 2012), 


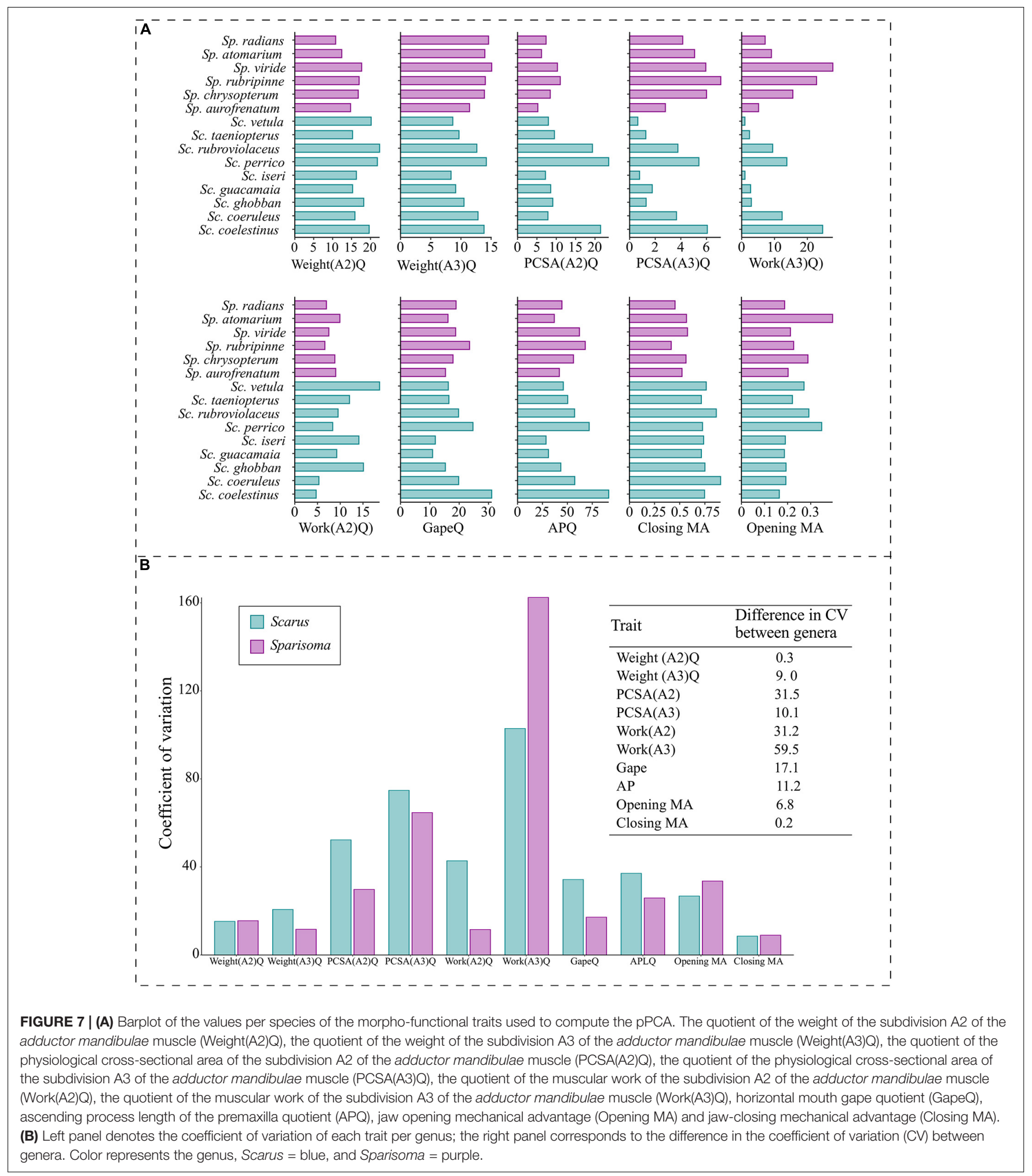

indicate that Scarus is younger than Sparisoma. The former appeared 8.02 mya ago (HPD: 5.01-10.9) compared to the latter, which appeared 12.53 mya (HPD: 7.7-17.8). In a relatively short evolutionary time, the genus Scarus exhibits greater morpho-functional disparity; it implies that the evolutionary rate has been high in this genus and that the ecological environment of reefs habitats played an essential role in its morpho-functional diversification (Kazancioglu et al., 2009; Price et al., 2010; Wainwright and Price, 2018). As it is proposed initially by Bellwood (1994), later by Bernardi et al. (2000), and supported by our own ancestral feeding mode reconstruction, the current functional groups displayed by the genus Sparisoma 
reflect the evolution of feeding modes of parrotfishes as a whole subfamily. Parrotfishes are proposed to have a browser ancestor, later excavators emerged and finally scrapers, as the most derived state (Bellwood, 1994). We could hypothesize then that Scarus reached an adaptive peak associated with inhabiting reefs, which constrained their ecological diversification but enhanced their feeding morphological diversification. Sparisoma species were initially exposed to seagrass beds and more recently to reefs (Streelman et al., 2002; Choat et al., 2012), diversified in their feeding modes despite being morphologically constrained.

\section{CONCLUSION}

We conclude that there are ecological forces that have shaped the feeding behavior and feeding ecology in different directions in both genera of American parrotfishes. Our results suggest that there is a decoupling between the disparity of jaw morphological traits and the feeding modes. Further research in the diversity of the feeding modes of parrotfishes will give us a better and more detailed understanding of the relationship between the ecology and morphology of these fishes. The faster rates of evolution in traits WorkA2 and PCSAA2 found in Scarus, together with the greater occupancy of morphological space and greater disparity, indicate few overlap and therefore limited convergence in this group, at least in the American species included in this study. Phylogenetic evidence indicates that the scraping feeding mode exhibited by scraping Sparisoma species and all the Scarus species is an evolutionary convergence that is not related to the morphology but their feeding activities on the reef. For ecological assessments of the impact of feeding by parrotfishes, using previously identified functional groups is reasonable. However, there is a need for more detailed studies, including a better resolution in terms of microhabitat utilization, dial variation among species, and other ecological aspects in the scraping feeding mode. We cannot prove that the intramandibular joint present in the Scarus species is the reason for their higher morpho-functional disparity. Therefore, our results highlight the importance of developing more detailed models for mandibular performance. The high morpho-functional diversity of Scarus species jaws, push us to develop new models to explain the mechanics of their biting performance. These new models should include measurements that evaluate the role of the intramandibular joint in the jaw movements and measurements of the adductor mandibulae muscles, which seems to be a great source of variation within the genus Scarus and probably also in Chlorurus and Hipposcarus. Finally, biogeography more than feeding ecological convergence may be paired with feeding mode evolution in both genera of American parrotfishes.

\section{REFERENCES}

Abramoff, M. D., Magalhães, P. J., and Ram, S. J. (2004). Image processing with Image. Biophotonics Int. 11, 36-42.

Aiello, B. R., Westneat, M. W., and Hale, M. E. (2017). Mechanosensation is evolutionarily tuned to locomotor mechanics. Proc. Natl.

\section{DATA AVAILABILITY STATEMENT}

The datasets presented in this study can be found in online repositories. The names of the repository/repositories and accession number(s) can be found in the article/ Supplementary Material.

\section{ETHICS STATEMENT}

The animal study was reviewed and approved by Universidad del Valle. Fish collection permit given by Parques Nacionales Naturales de Colombia.

\section{AUTHOR CONTRIBUTIONS}

JT conceived the study, obtained the samples and conducted the phylogenetic and comparative phylogenetic analyses. LPA did the morphological measurements, ran the jaw mechanical models, calculated the morphological disparity metrics, and did the data visualization. LPA drafted the manuscript, JT edited and reviewed it. Both authors contributed to the writing of this manuscript and approve its publication.

\section{ACKNOWLEDGMENTS}

Thanks to the Universidad del Valle and the Ichthyology Laboratory members. Thanks to prof. Fernando Zapata for his constant suggestions and support during the design of the project. Thanks to the "Bioerosion Project" lead by prof. Edgardo Londoño. Thanks to the Parques Nacionales Naturales de Colombia crew in Gorgona Island for the fieldwork help. Thanks to the project "Genetic diversity of parrotfishes in the south Caribbean," which provided the fish specimens from the Caribbean. And finally, thanks to Peter Wainwright and Maria del Rosario Castañeda for reading and commenting on early versions of this manuscript. Contribution number 18 from Instituto de Ciencias del Mar y Limnología (INCIMAR) de la Universidad del Valle, Colombia.

\section{SUPPLEMENTARY MATERIAL}

The Supplementary Material for this article can be found online at: https://www.frontiersin.org/articles/10.3389/fmars. 2021.634046/full\#supplementary-material

Acad. Sci. U.
39114 S. A. $114,4459-4464$.
llwood, D. R.


Bellwood, D. R., and Choat, J. H. (1990). A functional analysis of grazing in parrotfishes (family Scaridae): the ecological implications. Environ. Biol. Fishes 28, 189-214. doi: 10.1007/978-94-009-2065-1_11

Bellwood, D. R., Goatley, C. H. R., Bellwood, O., Delbarre, D. J., and Friedman, M. (2015). The rise of jaw protrusion in spiny-rayed fishes closes the gap on elusive prey. Curr. Biol. 25, 2699-2700.

Bernardi, G., Robertson, D. R., Clifton, K. E., and Azzurro, E. (2000). Molecular systematics, zoogeography, and evolutionary ecology of the atlantic parrotfish genus Sparisoma. Mol. Phylogenet. Evol. 15, 292-300. doi: 10.1006/mpev.1999. 0745

Blomberg, S. P., and Garland, T. (2002). Tempo and mode in evolution: Phylogenetic inertia, adaptation and comparative methods. J. Evol. Biol. 15, 899-910. doi: 10.1046/j.1420-9101.2002.00472.x

Bonaldo, R. M., Hoey, A. S., and Bellwood, D. R. (2014). "The ecosystem role of parrotfishes on tropical reefs," in Oceanography, Marine Biology, An Annual, and Review, eds R. N. Hughes and D. Hughes eds (Millton ParK: Smith), 81-132. doi: 10.1201/b17143-3

Bruggemann, J. H., Van Kessel, A. M., Van Rooij, J. M., and Breeman, A. M. (1996). Bioerosion and sediment ingestion by the caribbean parrotfish Scarus vetula and Sparisoma viride: implications of fish size, feeding mode and habitat use. Mar. Ecol. Prog. Ser. 134, 59-71. doi: 10.3354/meps134059

Burress, E. D., Martinez, C. M., and Wainwright, P. C. (2020). Decoupled jaws promote trophic diversity in cichlid fishes. Evolution 74, 950-961. doi: 10.1111/ evo. 13971

Cardoso, S. C., Soares, M. C., Oxenford, H. A., and Côté, I. M. (2009). Interspecific differences in foraging behaviour and functional role of Caribbean parrotfish. Mar. Biodivers. Rec. 2, 1-6.

Carlson, R. L., and Wainwright, P. C. (2010). The ecological morphology of darter fishes (Percidae: Etheostomatinae). Biol. J. Linn. Soc. 100, 30-45. doi: 10.1111/j. 1095-8312.2010.01417.x

Choat, J. H., Klanten, O. S., Van Herwerden, L., Robertson, D. R., and Clements, K. D. (2012). Pattern and process in the evolutionary history of parrotfishes (Family Labridae). Biol. J. Linn. Soc. 107, 529-557. doi: 10.1111/j.1095-8312. 2012.01959.x

Clements, K. D., German, D. P., Piché, J., Tribollet, A., and Choat, J. H. (2017). Integrating ecological roles and trophic diversification on coral reefs: multiple lines of evidence identify parrotfishes as microphages. Biol. J. Linn. Soc. 120, 729-751.

Collar, D. C., Near, T. J., and Wainwright, P. C. (2005). Comparative analysis of morphological diversity: does disparity accumulate at the same rate in two lineages of centrarchid fishes? Evolution 59, 1783-1794. doi: 10.1111/j.00143820.2005.tb01826.x

Cowman, P. F., Bellwood, D. R., and van Herwerden, L. (2009). Dating the evolutionary origins of wrasse lineages (Labridae) and the rise of trophic novelty on coral reefs. Mol. Phylogenet. Evol. 52, 621-631. doi: 10.1016/j.ympev.2009. 05.015

de Boer, B., van de Wal, R. S. W., Lourens, L. J., and Bintanja, R. (2012). Transient nature of the Earth's climate and the implications for the interpretation of benthic $\delta 18 \mathrm{O}$ records. Palaeogeogr. Palaeoclimatol. Palaeoecol. 33, 4-11. doi: 10.1016/j.palaeo.2011.02.001

Drummond, A. J., and Rambaut, A. (2007). BEAST: bayesian evolutionary analysis by sampling trees. BMC Evol. Biol. 7:214. doi: 10.1186/1471-2148-7-214

Edgar, R. C. (2004). MUSCLE: multiple sequence alignment with high accuracy and high throughput. Nucleic Acids Res. 32, 1792-1797. doi: 10.1093/nar/gkh340

Eschmeyer, W. N. (2019). Catalog of Fishes. Available online at: https: //www.calacademy.org/scientists/projects/eschmeyers-catalog-of-fishes [accessed February 15, 2019]

Ferry-Graham, L. A., and Konow, N. (2010). The intramandibular joint in Girella: a mechanism for increased force production? J. Morphol. 271, 271-279.

Foote, M. (1993). Discordance and concordance between morphological and taxonomic diversity. Paleobiology 19, 185-204. doi: 10.1017/ s0094837300015864

Foote, M. (1997). The Evolution of Morphological Diversity. Annu. Rev. Ecol. Syst. Annu. Rev. Ecol. 28, 129-152.

Frédérich, B., Olivier, D., Litsios, G., Alfaro, M. E., and Parmentier, E. (2014). Trait decoupling promotes evolutionary diversification of the trophic and acoustic system of damselfishes. Proc. R. Soc. B Biol. Sci. 281:20141047. doi: 10.1098/ rspb.2014.1047
Froese, R., and Pauly, D. (2017). FishBase. World Wide Web Electron. Publ. Available online at: www.fishbase.org [accessed December 2, 2017]

García-Navas, V., Noguerales, V., Cordero, P. J., and Ortego, J. (2017). Phenotypic disparity in Iberian short-horned grasshoppers (Acrididae): the role of ecology and phylogeny. BMC Evol. Biol. 17:109.

Gosline, W. A. (1981). The evolution of the premaxillary protrusion system in some teleostean fish groups. J. Zool. 193, 11-23. doi: 10.1111/j.1469-7998.1981. tb01487.x

Green, A. L., and Bellwood, D. R. (2009). Monitoring Functional Groups of Herbivorous Reef Fishes as Indicators of Coral Reef Resilience A practical guide for coral reef managers in the Asia Pacific Region. Gland: IUCN.

Grubich, J. R., Huskey, S., Crofts, S., Orti, G., and Porto, J. (2012). Mega-bites: extreme jaw forces of living and extinct piranhas (Serrasalmidae). Sci. Rep. 2:1009.

Guillerme, T. (2018). dispRity?: a modular R package for measuring disparity. Methods Ecol. Evol. 9, 1755-1763. doi: 10.1111/2041-210x.13022

Guillerme, T., Cooper, N., Brusatte, S. L., Davis, K. E., Jackson, A. L., Gerber, S., et al. (2020). Disparities in the analysis of morphological disparity. Biol. Lett. 16:20200199.

Harmon, L. J., Weir, J. T., Brock, C. D., Glor, R. E., and Challenger, W. (2008). GEIGER: investigating evolutionary radiations. Bioinformatics 24, 129-131. doi: 10.1093/bioinformatics/btm538

Harmon, L., Schulte, J. A., Larson, A., and Losos, J. B. (2003). Tempo and mode of evolutionary radiation in iguanian lizards. Science 301, 961-964. doi: 10.1126/ science. 1084786

Helfman, G. S., Collette, B. B., Facey, D. E., and Bowen, B. W. (2009). The Diversity of Fishes: Biology, Evolution, and Ecology. Hoboken, NJ: Wiley.

Huelsenbeck, J. P., Nielsen, R., and Bollback, J. P. (2003). Stochastic mapping of morphological characters. Syst. Biol. 52, 131-158. doi: 10.1080/ 10635150390192780

Hulsey, C. D., Hollingsworth, P. R., and Holzman, R. (2010). Co-evolution of the premaxilla and jaw protrusion in cichlid fishes (Heroine: Cichlidae). Biol. J. Linn. Soc. 100, 619-629. doi: 10.1111/j.1095-8312.2010.01468.x

Kazancioglu, E., Near, T. J., Hanel, R., and Wainwright, P. C. (2009). Influence of sexual selection and feeding functional morphology on diversification rate of parrotfishes (Scaridae). Proc. Biol. Sci. 276, 3439-3446. doi: 10.1098/rspb.2009. 0876

King, J. R., and Jackson, D. A. (1999). variable selection in large environmental data sets using principal components analysis. Environmetrics 10, 67-77. doi: 10.1002/(sici) 1099-095x(199901/02) 10:1<67::aid-env336>3.0.co;2-0

Konow, N., and Bellwood, D. R. (2011). Evolution of high trophic diversity based on limited functional disparity in the feeding apparatus of marine angelfishes (f. pomacanthidae). PLoS One 6:24113.

Konow, N., Bellwood, D. R., Wainwright, P. C., and Kerr, A. M. (2008). Evolution of novel jaw joints promote trophic diversity in coral reef fishes. Biol. J. Linn. Soc. 93, 545-555. doi: 10.1111/j.1095-8312.2007.00893.x

Lanfear, R., Calcott, B., Ho, S. Y. W., and Guindon, S. (2012). Partitionfinder: combined selection of partitioning schemes and substitution models for phylogenetic analyses. Mol. Biol. Evol. 29, 1695-1701. doi: 10.1093/molbev/ mss020

Lewis, S. (1986). The role of herbivorous fishes in the orgamization of a caribbean reef community. Ecol. Monogr. 56, 183-200. doi: 10.2307/2937073

Mao, Y., Economo, E. P., and Satoh, N. (2018). The roles of introgression and climate change in the rise to dominance of acropora corals. Curr. Biol. 28, 3373-3382.e5.

Miller, M. A., Schwartz, T., Pickett, B. E., He, S., Klem, E. B., Scheuermann, R. H., et al. (2015). A RESTful API for access to phylogenetic tools via the cipres science gateway. Evol. Bioinform. 11, 43-48.

Moen, D. S., Irschick, D. J., and Wiens, J. J. (2013). Evolutionary conservatism and convergence both lead to striking similarity in ecology, morphology and performance across continents in frogs. Proc. R. Soc. B Biol. Sci. 280:20132156. doi: $10.1098 / \mathrm{rspb} .2013 .2156$

Nanami, A. (2016). Parrotfish grazing ability: interspecific differences in relation to jaw-lever mechanics and relative weight of adductor mandibulae on an Okinawan coral reef. PeerJ 4:e2425. doi: 10.7717/peerj.2425

Nash, K. L., Graham, N. A. J., Wilson, S. K., and Bellwood, D. R. (2013). Cross-scale habitat structure drives fish body size distributions on coral reefs. Ecosystems 16, 478-490. doi: 10.1007/s10021-012-9625-0 
Nicholson, G. M., and Clements, K. D. (2021). Ecomorphological divergence and trophic resource partitioning in 15 syntopic Indo-Pacific parrotfishes (Labridae: Scarini). Biol. J. Linn. Soc. 132, 590-611. doi: 10.1093/biolinnean/blaa210

O’Meara, B. C., Ané, C., Sanderson, M. J., and Wainwright, P. C. (2006). Testing for different rates of continuous trait evolution using likelihood. Evolution 60:922. doi: 10.1111/j.0014-3820.2006.tb01171.x

Olivier, D., Gajdzik, L., Parmentier, E., and Frédérich, B. (2017). Evolution and diversity of ram-suction feeding in damselfishes (Pomacentridae). Org. Divers. Evol. 17, 497-508. doi: 10.1007/s13127-017-0329-3

Parenti, P., and Randall, J. E. (2011). Checklist of the species of the families Labridae and Scaridae: an update. Smithiana Bull. 13, 29-44.

Pigot, A. L., Sheard, C., Miller, E. T., Bregman, T. P., Freeman, B. G., Roll, U., et al. (2020). Macroevolutionary convergence connects morphological form to ecological function in birds. Nat. Ecol. Evol. 4, 230-239. doi: 10.1038/s41559019-1070-4

Price, S. A., Wainwright, P. C., Bellwood, D. R., Kazancioglu, E., Collar, D. C., and Near, T. J. (2010). Functional innovations and morphological diversification in parrotfish. Evolution 64, 3057-3068.

R Development Core Team (2013). R: a Language and Environment for Statistical Computing. Vienna: R Found Statistical Computing.

Rambaut, A., Suchard, M., Xie, D., and Drummond, A. (2014). Tracer Version 1.6.

Reaney, A. M., Saldarriaga-Córdoba, M., and Pincheira-Donoso, D. (2018). Macroevolutionary diversification with limited niche disparity in a species-rich lineage of cold-climate lizards. BMC Evol. Biol. 18:16.

Renema, W., Pandolfi, J. M., Kiessling, W., Bosellini, F. R., Klaus, J. S., Korpanty, C., et al. (2016). Are coral reefs victims of their own past success? Sci. Adv. 2:e1500850. doi: 10.1126/sciadv.1500850

Revell, L. J. (2009). Size-correction and principal components for interspecific comparative studies. Evolution 63, 3258-3268. doi: 10.1111/j.1558-5646.2009. 00804.x

Revell, L. J. (2012). phytools: an R package for phylogenetic comparative biology (and other things). Methods Ecol. Evol. 3, 217-223. doi: 10.1111/j.2041-210x. 2011.00169.x

Robertson, R. D., and Allen, G. R. (2015). Shorefishes of the Tropical Eastern Pacific: Online Information System. Version 2.0 Smithson.

Robertson, R. D., and Van Tassell, J. L. (2015). Shorefishes of the Greater Caribbean: Online Information System. Version 1.0 Smithson.

Russ, G. (1984). Distribution and abundance of herbivorous grazing fishes in the central great barrier reef. i. levels of variability across the entire continental shelf. Mar. Ecol. Prog. Ser. 20, 23-34. doi: 10.3354/meps02 0023

Sayers, E. W., Barrett, T., Benson, D. A., Bolton, E., Bryant, S. H., Canese, K., et al. (2011). Database resources of the national center for biotechnology information. Nucleic Acids Res. 39, 38-51.

Siqueira, A. C., Bellwood, D. R., and Cowman, P. F. (2019a). Historical biogeography of herbivorous coral reef fishes: the formation of an Atlantic fauna. J. Biogeogr. 46, 1611-1624.

Siqueira, A. C., Bellwood, D. R., and Cowman, P. F. (2019b). The evolution of traits and functions in herbivorous coral reef fishes through space and time. Proc. $R$. Soc. B Biol. Sci. 286:20182672. doi: 10.1098/rspb.2018.2672

Slater, G. J., Price, S. A., Santini, F., and Alfaro, M. E. (2010). Diversity versus disparity and the radiation of modern cetaceans. Proc. R. Soc. B Biol. Sci. 277, 3097-3104. doi: 10.1098/rspb.2010.0408

Smith, L. L., Fessler, J. L., Alfaro, M. E., Streelman, J. T., and Westneat, M. W. (2008). Phylogenetic relationships and the evolution of regulatory gene sequences in the parrotfishes. Mol. Phylogenet. Evol. 49, 136-152. doi: 10.1016/ j.ympev.2008.06.008

Streelman, J. T., Alfaro, M., Westneat, M. W., Bellwood, D. R., and Karl, S. (2002). Evolutionary history of the parrotfishes: biogeography, ecomorphology, and comparative diversity. Evolution 56, 961-971. doi: 10.1111/j.0014-3820.2002. tb01408.x

Taylor, B. M., Trip, E. D. L., and Choat, J. H. (2018). "Dynamic demography: investigations of life-history variation in the parrotfishes," in Biology of Parrotfishes, eds A. S. Hoey and B. Roberta (Boca Raton: CRC Press).

Thompson, J. D., Higgins, D. G., and Gibson, T. J. (1994). CLUSTAL W: improving the sensitivity of progressive multiple sequence alignment through sequence weighting, position-specific gap penalties and weight matrix choice. Nucleic Acids Res. 22, 4673-4680. doi: 10.1093/nar/22.22.4673

Vermeij, G. J. (1973). Adaptation, versatility, and evolution. Soc. Syst. Biol. 22, 466-477. doi: 10.2307/2412953

Wainwright, P. C., Alfaro, M. E., Bolnick, D. I., and Hulsey, C. D. (2005). Manyto-one mapping of form to function: a general principle in organismal design? Integr. Comp. Biol. 45, 256-262. doi: 10.1093/icb/45.2.256

Wainwright, P. C., and Price, S. A. (2018). “"Innovation and diversity of the feeding mechanism in parrotfishes,", in Biology of Parrotfishes, eds A. S. Hoey and R. Bonaldo (Boca Raton: CRC Press), 26-41. doi: 10.1201/9781315118079-2

Wainwright, P. C., and Richard, B. A. (1995). Predicting patterns of prey use from morphology of fishes. Environ. Biol. Fishes 44, 97-113. doi: 10.1007/978-94017-1356-6_7

Wainwright, P. C., Bellwood, D. R., Westneat, M. W., Grubich, J. R., and Hoey, A. S. (2004). A functional morphospace for the skull of labrid fishes: patterns of diversity in a complex biomechanical system. Biol. J. Linn. Soc. 82, 1-25. doi: 10.1111/j.1095-8312.2004.00313.x

Westneat, M. W. (2003). A biomechanical model for analysis of muscle force, power output and lower jaw motion in fishes. J. Theor. Biol. 223, 269-281. doi: 10.1016/s0022-5193(03)00058-4

Westneat, M. W. (2004). Evolution of levers and linkages in the feeding mechanisms of fishes. Integr. Compar. Biol. 44, 378-389. doi: 10.1093/icb/44. 5.378

Westneat, M. W., and Alfaro, M. E. (2005). Phylogenetic relationships and evolutionary history of the reef fish family Labridae. Mol. Phylogenet. Evol. 36, 370-390. doi: 10.1016/j.ympev.2005.02.001

Wroe, S., Mchenry, C., and Thomason, J. (2005). Bite club: comparative bite force in big biting mammals and the prediction of predatory behaviour in fossil taxa. Proc. R. Soc. B 272, 619-625. doi: 10.1098/rspb.2004.2986

Young, R. L., Sweeney, M. J., and Badyaev, A. V. (2010). Morphological diversity and ecological similarity: versatility of muscular and skeletal morphologies enables ecological convergence in shrews. Funct. Ecol. 24, 556-565. doi: 10. 1111/j.1365-2435.2009.01664.x

Conflict of Interest: The authors declare that the research was conducted in the absence of any commercial or financial relationships that could be construed as a potential conflict of interest.

Copyright (C) 2021 Pombo-Ayora and Tavera. This is an open-access article distributed under the terms of the Creative Commons Attribution License (CC BY). The use, distribution or reproduction in other forums is permitted, provided the original author(s) and the copyright owner(s) are credited and that the original publication in this journal is cited, in accordance with accepted academic practice. No use, distribution or reproduction is permitted which does not comply with these terms. 